\title{
A Fuzzy Multi-Attribute Decision Making Model for Strategic Risk Assessment
}

\author{
Rabia Arikan* \\ Department of Industrial Engineering, Gazi University \\ Ankara, 06570, Turkey \\ Metin Dağdeviren \\ Department of Industrial Engineering, Gazi University \\ Ankara, 06570, Turkey \\ E-mail: metindag@gazi.edu.tr \\ Mustafa Kurt \\ Department of Industrial Engineering, Gazi University \\ Ankara, 06570, Turkey \\ E-mail:mkurt@gazi.edu.tr \\ Received 5 March 2012 \\ Accepted 6 January 2013
}

\begin{abstract}
Risk assessment is a very important issue for an effective institution, since the lack of accurate risk assessment method or the improper risk management might cause problems to achieve institutions' strategic objectives. There are a finite number of risks which have to be ranked considering many different and conflicting criteria. In this respect, assessing risks by relating to strategic objectives is a multi-attribute decision making problem. In this study, an integrated approach which employs analytic hierarchy process (AHP) and fuzzy logarithmic least squares method (LLSM) together is proposed for the strategic risk assessment problem. The AHP is used to analyze the structure of the risk assessment problem and to determine weights of the criteria, and fuzzy LLSM method is used to obtain final ranking. Proposed approach is applied to a problem of prioritizing risks in a public institution.
\end{abstract}

Keywords: Risk assessment, multi attribute decision making, fuzzy analytic hierarchy process, fuzzy logarithmic least squares method

* Corresponding author. Tel.: +90 3122046155; fax: +90 3122047441. E-mail address: rabiacanbolat@ gmail.com Web address: $\underline{\text { www.mf.gazi.edu.tr }}$ 


\section{Introduction}

Risk assessment has a big role to achieve organizational effectiveness and it is one of the most important processes in public management literature as accurate risk management is critical for judging the success or failure of a public institution. For this reason, risks must be carefully identified, assessed and monitored.

The risk assessment process can be complex because of the complexity of the modeling required and the often subjective nature of the data available to conduct the analysis. However, the complexity of the process is not overwhelming and the benefits of the outcome can be extremely valuable ${ }^{1}$.

On the other hand, there is not a specific "standard" set for risk management in public institutions. This is the primary problem with this issue. Institutions may choose to adopt particular standards. More important than compliance with any particular standard is ability to demonstrate that risk is managed in the particular organization, in its particular circumstances, in a way which effectively supports the delivery of its objectives $^{2}$. Within this scope, this paper proposed to assess and prioritize risks by relating to strategic objectives and strategic steps (activities).

In the literature there are many methods proposed or developed in order to assess or prioritize risks. These methods range from simple, empirical methods to computationally complex, statistically based methods ${ }^{1}$. UK Treasury used most traditional risk assessment method which evaluates occurrence of the risk being realized and of the severity if the risk is realized ${ }^{2}$. This approach is preferred with different scales by many different organizations. A categorization of high / medium / low in respect of each may be sufficient, and should be the minimum level of categorization. A more detailed analytical scale may be appropriate, especially if clear quantitative evaluation can be applied to the particular risk ${ }^{2}$. Bonvicini et al. ${ }^{3}$ proposed Laboratory Assessment and Risk Analysis methodology, which relied on defining the adequate role player factors to assess risks in research environment and their mathematical combination to quantify and assess the risk. Frantzich ${ }^{4}$ demonstrated how two quantitative risk analysis methods may be used to evaluate the risk to which the occupants of a building may be subjected if a fire breaks out by using Monte Carlo simulations. McGill, Ayyub and Kaminskiy ${ }^{5}$, Han and Weng ${ }^{6}$ proposed quantitative risk analysis methods for different sectors. Bailer et al. ${ }^{7}$, Kelly and Smith $^{8}$, Nordgard and Sand $^{9}$ suggested the application of Bayesian analysis and networks for risk assessment. Sikder et al. ${ }^{10}$ proposed a novel approach to risk assessment by using a dominance-based rough set approach to account for preference order in the domains of attributes in the set of risk classes. Pan et al. ${ }^{11}$ improved a new risk estimation framework and applied on an aluminum extrusion industry's worksite. Wang et al. ${ }^{12}$ proposed an integrated AHP-DEA (data envelopment analysis) methodology for bridge risk assessment. Schulz et al. ${ }^{13}$ suggested the use of geodata-based probabilistic method to assess risks. Aven and Heide ${ }^{14}$ focused on reliability and validity of risk analysis. Srivastava and Gupta ${ }^{15}$ improved a Security Risk Factor Table (SRFT) and a Stepped Matrix Procedure (SMP) to assess the security risk of oil and gas industry. Dash ${ }^{16}$ studied about risk assessment techniques for software development. Syachrani et al. ${ }^{17}$ proposed matrix method to risk management for culvert rehabilitation. Mousavi et al. ${ }^{18}$ suggested the use of jackknife technique to risk assessment for highway projects.

A number of fuzzy methods, have been developed and proposed to assess and manage risks (Refs. 19-26). Also, there are many studies improved in order to analyze risks by using fuzzy numbers (Refs. 27-40).

In the risk assessment problem, there are a finite number of risks which have to be ranked considering many different and conflicting criteria. Accordingly, this problem is considered as a multi attribute decision making problem. Multi attribute decision making methods such as analytic hierarchy process (AHP) (Refs. 41-46), analytic network process (ANP) (Refs. 47-49), TOPSIS (Ref. 50) and PROMETHEE (Ref. 51) used for risk assessment problems in the literature. Some of these methods are systematic approaches to the alternative selection and justification problem by using the concepts of fuzzy set theory and hierarchical structure analysis. Decision makers usually find that it is more confident to give interval judgements than fixed value judgements ${ }^{52}$.

In this paper, AHP-fuzzy logarithmic least squares method (LLSM) integrated approach for assessing risks will be introduced and the implementation process will be explained with a real world example. We used the AHP method to analyze the structure of the risk assessment problem and determine the weights of criteria. The normalization of interval and fuzzy weights is often necessary in multi attribute decision making under uncertainty, especially in AHP with interval or fuzzy judgements ${ }^{53}$. Therefore we used Wang's fuzzy LLSM approach to normalize local fuzzy weights and obtain final ranking. 
AHP could be a useful tool because of its ability to handle both qualitative and quantitative decision criteria. Unfortunately, this approach is inadequate at addressing the uncertainties common in real-life applications $^{46}$. For this reason, this paper integrated fuzzy LLSM with AHP to form a risk assessment model.

The main contribution of this study is to establish a risk assessment model by considering interactions among the strategic objectives, strategic steps (activities) and risks, in the strategic risk assessment process for public institutions.

The other expected improvement and the main difference of this study from the other studies in the literature and its contribution to the related literature is related to the scoring in the risk assessment. Opinions of the experts over criteria and alternatives can be evaluated in the construction of the model.

Some types of risk lend themselves to a numerical diagnosis particularly financial risk. For other risks, for example reputational risk, a much more subjective view is all that is possible ${ }^{2}$. In this regard, traditional risk assessment method is inadequate at dealing with uncertainty and subjectivity of risk assessment problem. Within this scope this paper points out inadequacy of traditional risk assessment methods in the evaluation of subjective risks and suggests a model tries to eliminate the vagueness and insufficiency via fuzzy LLSM approach in the $\mathrm{AHP}^{54}$.

The rest of the paper is organized as follows. In Section 2, we briefly review the fuzzy LLSM and modified fuzzy LLSM approach ${ }^{54}$. In Section 3, we determine the steps of the proposed model in detail. How to proposed model is used on a real world example is explained in Section 4. In Section 5, conclusions are discussed.

\section{Method}

\subsection{Fuzzy AHP}

AHP was first introduced by Saaty ${ }^{55}$ and used in different decision-making process (Refs. 56-59). The multi-criteria decision making methods such as AHP require exact judgments. However, due to the complexity and uncertainty involved in real world decision problems, it is sometimes unrealistic or even impossible to require exact judgments. It is therefore more natural or realistic that a decision maker is allowed to provide fuzzy judgments instead of precise comparisons $^{54}$. A number of methods (Refs. 53, 54, 6073) have been developed to deal with fuzzy comparison matrices. Wang et al. ${ }^{54}$, discussed the fuzzy LLSM proposed by Van Laarhoven and Pedrycz ${ }^{60}$ and modified by Boender et al. ${ }^{62}$. It is found that the fuzzy LLSM cannot always be solved as an unconstrained optimization model. In the situation that the lower bound value of a non-normalized fuzzy weight turns out to be greater than its upper bound value, there exists no appropriate normalization method that can make the normalized fuzzy weight make sense. It is also found that the local fuzzy weights of incomplete fuzzy comparison matrices are uncertain and the aggregation method of local fuzzy weights into global ones is problematic. As it can be seen from the reasons mentioned above, modifications need to be done to keep the fuzzy LLSM useful ${ }^{54}$. Therefore, we prefer Wang et al.'s ${ }^{54}$ modified fuzzy LLSM approach in this study.

\subsection{Fuzzy $L L S M$}

Consider a group triangular fuzzy comparison matrix expressed by $\tilde{\mathrm{A}}$ where $\tilde{\mathrm{a}}_{i j k}=\left(l_{i j k}, m_{i j k}, u_{i j k}\right)$ are triangular fuzzy judgements with $\tilde{\mathrm{a}}_{i j k}=\tilde{\mathrm{a}}_{j i k}{ }^{-1}=\left(1 / u_{i j k}\right.$, $\left.1 / m_{i j k}, 1 / l_{i j k}\right)$ for $i, j=1, \ldots, n, i \neq j, k=1, \ldots, \delta_{\mathrm{ij}}$ and $\delta_{\mathrm{ij}}=\delta_{\mathrm{ji}}$. If $\delta_{\mathrm{ij}}=0$, then there is no judgement that has been made about $\tilde{a}_{\mathrm{i} j}$, which is denoted as '-'.

For the above group triangular fuzzy comparison matrix $\tilde{A}$, there should exist a normalized triangular fuzzy weight vector, $\widetilde{W}=\left(\widetilde{w}_{1}, \ldots ., \widetilde{w}_{T}\right)^{T}=$ $\left(\left(w_{1}^{L}, w_{1}^{M}, w_{1}^{U}\right), \ldots,\left(w_{n}^{L}, w_{n}^{M}, w_{n}^{U}\right)\right)^{T}$, which is close to $\tilde{\mathrm{A}}$ in the sense that

$\tilde{a}_{i j k}=\left(l_{i j k}, m_{i j k}, u_{i j k}\right) \approx \widetilde{w}_{i} / \widetilde{w}_{j} \approx\left(w_{i}^{L} / w_{j}^{U}, w_{i}^{M} / w_{j}^{M}\right.$, $\left.w_{i}^{U} / w_{j}^{L}\right), i, j=1, \ldots, n ; i \neq j, k=1, \ldots ., \delta_{\mathrm{ij} .}$.

To determine the fuzzy weight vector $\widetilde{W}$, the following fuzzy logarithmic least squares model can be constructed $^{54}$ :

$$
\begin{aligned}
& \operatorname{Min} J=\sum_{i=1}^{n} \sum_{j=1, j \neq i}^{n} \sum_{k=1}^{\delta_{i j}}\left(\left(\ln w_{i}^{L}-\ln w_{j}^{U}-\ln a_{i j k}^{L}\right)^{2}\right. \\
& +\left(\ln w_{i}^{M}-\ln w_{j}^{M}-\ln a_{i j k}^{M}\right)^{2}+\left(\ln w_{i}^{U}-\ln w_{j}^{L}-\right. \\
& \left.\left.\ln a_{i j k}^{U}\right)^{2}\right) \\
& \text { Let } \frac{\partial J}{\partial w_{i}^{L}}=0, \frac{\partial J}{\partial w_{i}^{M}}=0 \text { and } \frac{\partial J}{\partial w_{i}^{U}}=0 \text { for } i=1, \ldots, n . \text { It }
\end{aligned}
$$

follows that 


$$
\begin{gathered}
\frac{\partial J}{\partial w_{i}^{L}}=\frac{2}{w_{i}^{L}} \sum_{j=1, j \neq i}^{n} \sum_{k=1}^{\delta_{i j}}\left(\ln w_{i}^{L}-\ln w_{j}^{U}-\ln a_{i j k}^{L}\right) \\
\frac{\partial J}{\partial w_{i}^{M}}=\frac{2}{w_{i}^{M}} \sum_{j=1, j \neq i}^{n} \sum_{k=1}^{\delta_{i j}}\left(\ln w_{i}^{M}-\ln w_{j}^{M}-\ln a_{i j k}^{M}\right) \\
\frac{\partial J}{\partial w_{i}^{U}}=\frac{2}{w_{i}^{U}} \sum_{j=1, j \neq i}^{n} \sum_{k=1}^{\delta_{i j}}\left(\ln w_{i}^{U}-\ln w_{j}^{L}-\ln a_{i j k}^{U}\right)
\end{gathered}
$$

which can be equivalently rewritten as

$$
\begin{aligned}
& l_{i}\left(\sum_{j=1, j \neq i}^{n} \delta_{i j}\right) \sum_{j=1, j \neq i}^{n} \delta_{i j} u_{j}=\sum_{j=1, j \neq i}^{n} \sum_{k=1}^{\delta_{i j}}\left(\ln a_{i j k}^{L}\right), \\
& m_{i}\left(\sum_{j=1, j \neq i}^{n} \delta_{i j}\right) \sum_{j=1, j \neq i}^{n} \delta_{i j} m_{j}=\sum_{j=1, j \neq i}^{n} \sum_{k=1}^{\delta_{i j}}\left(\ln a_{i j k}^{M}\right), \\
& u_{i}\left(\sum_{j=1, j \neq i}^{n} \delta_{i j}\right) \sum_{j=1, j \neq i}^{n} \delta_{i j} l_{j}=\sum_{j=1, j \neq i}^{n} \sum_{k=1}^{\delta_{i j}}\left(\ln a_{i j k}^{U}\right),
\end{aligned}
$$

where $i=1, \ldots, n, l_{i}=\ln w_{i}^{L}, m_{i}=\ln w_{i}^{M}$ and $u_{i}=\ln w_{i}^{U}$. Due to the reciprocity of judgement elements, Eqs. (6) and (8) always sum up to zero and are therefore linear dependent. This is also true for Eq.(7).

It is easy to find that if $\left(l_{i}, m_{i}, u_{i}\right)(i=1, \ldots, n)$ is a solution to Eqs. (6) and (8), then $\left(l_{i}+p_{1}, m_{i}+p_{2}, u_{i}+\right.$ $\left.p_{1}\right)(i=1, \ldots, n)$ is also one of their solutions, where $p_{1}$ and $\mathrm{p}_{2}$ are arbitrarily chosen constants. So, the fuzzy weights to be estimated can generally be expressed as

$\widetilde{w}_{i} \approx\left(\exp \left(l_{i}+p_{1}\right), \exp \left(m_{i}+p_{2}\right), \exp \left(u_{i}+p_{1}\right)\right)$, $(i=1, \ldots, n)$.

After normalization, Eq. (9) becomes

$\widetilde{w}_{i} \approx\left(\frac{\exp \left(l_{i}\right)}{\sum_{i=1}^{n} \exp \left(u_{i}\right)}, \frac{\exp \left(m_{i}\right)}{\sum_{i=1}^{n} \exp \left(m_{i}\right)}, \frac{\exp \left(u_{i}\right)}{\sum_{i=1}^{n} \exp \left(l_{i}\right)}\right)$

$(i=1, \ldots, n)$.

In the case of hierarchical structure, the local fuzzy weights are aggregated into global fuzzy weights by using fuzzy arithmetic. That is

$$
\widetilde{w}_{A i}=\sum_{j=1}^{m} \widetilde{w}_{j} \otimes \widetilde{w}_{i j} \approx\left(\sum_{j=1}^{m} w_{j}^{L} w_{i j}^{L}, \sum_{j=1}^{m} w_{j}^{M} w_{i j}^{M}, \sum_{j=1}^{m} w_{j}^{U} w_{i j}^{U}\right)
$$

$(i=1, \ldots, n)$,

where $\widetilde{w}_{j}=\left(w_{j}^{L}, w_{j}^{M}, w_{j}^{U}\right) \quad(j=1, \ldots, m)$ are the fuzzy weights of $m$ upper level criteria, $\widetilde{w}_{i j}=\left(w_{i j}^{L}, w_{i j}^{M}, w_{i j}^{U}\right)$ $(i=1, \ldots, n)$ are the fuzzy weights of $n$ lower level alternatives with respect to $j$ th upper level criterion, and $\widetilde{\mathrm{w}}_{\mathrm{Ai}}(\mathrm{i}=1, \ldots, \mathrm{n})$ are the global fuzzy weights of the $n$ lower level alternatives ${ }^{54}$.

\subsection{Modified fuzzy LLSM}

A number of methods have been developed to deal with fuzzy comparison matrices, as mentioned above. In this study, we prefer Wang et al.'s ${ }^{54}$ fuzzy LLSM approach because this method tackle the other methods' incorrectness in the normalization of local fuzzy weights, infeasibility in deriving the local fuzzy weights of a fuzzy comparison matrix when the lower bound value of a non-normalized fuzzy weight turns out to be greater than its upper bound value, uncertainty of local fuzzy weights for incomplete fuzzy comparison matrices, and unreality of global fuzzy weights ${ }^{54}$.

The modified fuzzy LLSM is formulated as a constrained nonlinear optimization model and can directly derive normalized triangular fuzzy weights for both complete and incomplete triangular fuzzy comparison matrices. The examination of the numerical example showed the advantages of the modified fuzzy LLSM in the AHP and its applicability in solving complex multi-criteria decision making problems.

First, the normalization constraints can be expressed as according to Wang et al.'s ${ }^{54}$ fuzzy LLSM approach;

$w_{i}^{L}+\sum_{j=1, j \neq i}^{n} w_{j}^{U} \geq 1, i=1, \ldots, n$,

$\sum_{i=1}^{n} w_{i}^{M} \geq 1$,

$w_{i}^{U}+\sum_{j=1, j \neq i}^{n} w_{j}^{L} \leq 1, i=1, \ldots, n$.

Next, it is found that normalized fuzzy weights cannot uniquely be determined from a fuzzy comparison matrix.

All triangular fuzzy weights meet the constraints of (12)-(14) and therefore are all normalized triangular fuzzy weights. In fact, if $\widetilde{W}=\left(\widetilde{w}_{1}, \ldots, \widetilde{w}_{T}\right)^{T}=$ $\left(\left(w_{1}^{L}, w_{1}^{M}, w_{1}^{U}\right), \ldots,\left(w_{n}^{L}, w_{n}^{M}, w_{n}^{U}\right)\right)^{T}$ is an optimal and normalized fuzzy weight estimate for some triangular fuzzy comparison matrix, then $\widetilde{W}^{\prime}=\left(\widetilde{w}_{1}^{\prime}, \ldots, \widetilde{w}_{T}^{\prime}\right)^{T}=\left(\left(k w_{1}^{L}, k w_{1}^{M}, k w_{1}^{U}\right)\right.$, 
$\left.\ldots,\left(k w_{n}^{L}, k w_{n}^{M}, k w_{n}^{U}\right)\right)^{T}$ is also an optimal and normalized fuzzy weight estimate for this triangular fuzzy comparison matrix when the parameter $k$ meets the following constraints:

$k w_{i}^{L} \leq w_{i}^{M} \leq k w_{i}^{U}, i=1, \ldots, n$,

$k \sum_{i=1}^{n} w_{i}^{U}-k \max _{j}\left(w_{j}^{U}-w_{j}^{L}\right) \geq 1$,

$k \sum_{i=1}^{n} w_{i}^{L}-k \max _{j}\left(w_{j}^{U}-w_{j}^{L}\right) \leq 1$.

The non-uniqueness of normalized fuzzy weights brings difficulty and inconvenience for the comparison and ranking of fuzzy weights as well as the synthesis of local fuzzy weights. Therefore, it is essential that a common benchmark of comparison should be set up so that local and global fuzzy weights can be derived with respect to the same reference point, i.e. benchmark. To set up such a benchmark for each fuzzy comparison, we use the following auxiliary equality constraint, which was first adopted by Jiménez et al. ${ }^{74}$ for normalizing a set of interval weights:

$\sum_{i=1}^{n}\left(w_{i}^{L}+w_{i}^{U}\right)=2$.

Theoretically, there is no evidence to support such an auxiliary equality constraint. However, due to the fact that $\sum_{i=1}^{n} w_{i}^{U}-\max _{j}\left(w_{j}^{U}-w_{j}^{L}\right) \geq 1 \quad$ and $\sum_{i=1}^{n} w_{i}^{L}-\max _{j}\left(w_{j}^{U}-w_{j}^{L}\right) \leq 1$, it is feasible to impose such an equality constraint $\sum_{i=1}^{n}\left(w_{i}^{L}+w_{i}^{U}\right)=2$. In particular, if normalized fuzzy weights are symmetrical, (18) will hold precisely. More importantly, by imposing such an equality constraint we can uniquely determine a set of normalized fuzzy weights for each fuzzy comparison matrix. Moreover, such a linear equality constraint makes our modified fuzzy least squares model (19) much easier to compute than any other nonlinear equality constraints such as $\left(\sum_{i=1}^{n} w_{A i}^{L}\right)\left(\sum_{i=1}^{n} w_{A i}^{U}\right)=1$, which has been proven to be incorrect in $^{50}$. Finally, based on the above analyses, the proposed modified fuzzy LLSM is formulated as follows:

MinJ $=\sum_{i=1}^{n} \sum_{j=1, j \neq i}^{n} \sum_{k=1}^{\delta_{i j}}\left(\left(\ln w_{i}^{L}-\ln w_{j}^{U}-\ln a_{i j k}^{L}\right)^{2}+\right.$

$\left(\ln w_{i}^{M}-\ln w_{j}^{M}-\ln a_{i j k}^{M}\right)^{2}+\left(\ln w_{i}^{U}-\ln w_{j}^{L}-\ln a_{i j k}^{U}\right)^{2}$ s.t.

$w_{i}^{L}+\sum_{j=1, j \neq i}^{n} w_{j}^{U} \geq 1$,

$w_{i}^{U}+\sum_{j=1, j \neq i}^{n} w_{j}^{L} \geq 1$,

$\sum_{i=1}^{n} w_{i}^{M}=1, \quad i=1, \ldots, n$

$\sum_{i=1}^{n}\left(w_{i}^{L}+w_{i}^{U}\right)=2$,

$w_{i}^{u} \geq w_{i}^{M} \geq w_{i}^{L}>0$,

which is a constrained nonlinear optimization model, whose constraints are all linear, and can be solved without difficulty by Microsoft Excel Solver or professional optimization software packages such as LINGO, GAMS or MATLAB. The optimum solution to the above model directly forms normalized fuzzy weights.

The global fuzzy weights can be obtained by solving the following two linear programming (LP) models and an equation for each alternative $A_{i}(i=1, \ldots, n)$ :

$w_{A i}^{L}=\operatorname{Min}_{W \in \Omega_{W}} \sum_{j=1}^{m} w_{i j}^{L} w_{j}, \quad i=1, \ldots, n$

$w_{A i}^{U}=\operatorname{Max}_{W \in \Omega_{W}} \sum_{j=1}^{m} w_{i j}^{U} w_{j}, \quad i=1, \ldots, n$

$w_{A i}^{M}=\sum_{j=1}^{m} w_{i j}^{M} w_{j}^{M}, \quad i=1, \ldots, n$

where $\quad \Omega_{W}=\left\{W=\left(w_{1}, \ldots, w_{n}\right)^{T} \mid w_{j}^{L} \leq w_{j} \leq w_{j}^{U}\right.$ $\left.\sum_{j=1}^{m} w_{j}=1, j=1, \ldots, m\right\}$ is a set (or space) of weights. Note that the global fuzzy weights are only approximate triangular fuzzy numbers, whose precise membership functions can be obtained by using $\alpha$-level sets and the extension principle ${ }^{75}$ but this requires more computational effort ${ }^{54}$.

Wang et al.'s ${ }^{54}$ theorem shows that the global weights obtained by (20)-(22) are always normalized if the local weights are normalized triangular fuzzy weights.

\section{Proposed Model}

The suggested model for the prioritization of risks includes the steps as following:

Step 1: Identify the criteria and alternatives to be used in the model.

Step 2: Structure the AHP model hierarchically (goal, 1st level criteria, 2nd level criteria, alternatives) 
Table 1. Linguistic scales for difficulty and importance

\begin{tabular}{cccc}
\hline Linguistic Scale for Difficulty & Linguistic Scale for Importance & $\begin{array}{c}\text { Triangular Fuzzy } \\
\text { Scale }\end{array}$ & $\begin{array}{c}\text { Triangular Fuzzy } \\
\text { Reciprocal Scale }\end{array}$ \\
\hline Just Equal & Just Equal & $(1,1,1)$ & $(1,1,1)$ \\
Equally difficult (ED) & Equally important (EI) & $(1 / 2,1,3 / 2)$ & $(1,3 / 2,2)$ \\
Weakly more difficult (WMD) & Weakly more important (WMI) & $(3 / 2,2,1,2)$ & $(1 / 2,2 / 3,1)$ \\
Strongly more difficult (SMD) & Strongly more important (SMI) & $(2,5 / 2,3)$ & $(1 / 3,2 / 5,1 / 2)$ \\
Very strongly more difficult (VSMD) & Very strongly more important (VSMI) & $(5 / 2,3,7 / 2)$ & $(2 / 7,1 / 3,2 / 5)$ \\
Absolutely more difficult (AMD) & Absolutely more important (AMI) & & \\
\hline
\end{tabular}

Step 3: Determine the relative importance of the criteria by using triangular fuzzy comparison matrix. The fuzzy scale regarding relative importance to measure the relative weights is given in Table 1. This scale is proposed by Kahraman et al. ${ }^{58}$ and used for solving fuzzy decision-making problems (Refs. 58, 59, 76) in the literature. This scale will be used in Wang et al.'s ${ }^{54}$ fuzzy prioritization approach.

Step 4: Compare 2nd level criteria under each of the 1 st level criteria separately.

Step 5: Determine the local weights of the 1st level criteria by solving model (19) for each of the comparison matrices.

Step 6: Calculate the global fuzzy weights of the 2nd level criteria by Eqs. (20)-(22) .

Step 7: Compare alternatives (risks) under each of the 2nd level criteria separately.

Step 8: Calculate the global fuzzy weights of the alternatives (risks). The global fuzzy weights of the 2nd level criteria, determined in Step 6, are used as relative importance values.

Step 9: Defuzzify global fuzzy weights using Converting the Fuzzy data into Crisp Scores (CFCS) Method. The method for defuzzification used in this paper is CFCS method introduced by Opricovic and Tzeng ${ }^{77}$. The CFCS method can clearly express fuzzy perception, which is based on the procedure of determining the lower and upper scores by fuzzy min and fuzzy max, and the total score is determined as a weighted average according to the membership functions ${ }^{78}$. The steps of CFCS method are as follow ${ }^{77}$ :

(i) Normalization

$$
u_{i}^{\max }=\max u_{i j}, \quad l_{i}^{\min }=\operatorname{minl}_{i j}
$$$$
\Delta_{\min }^{\max }=u_{i}^{\max }-l_{i}^{\min }
$$

compute for all alternatives $\mathrm{a}_{\mathrm{j}}, j=1, \ldots, J$

$$
x_{l j}=\left(l_{i j}-l_{i}^{\min }\right) / \Delta_{\min }^{\max }
$$

$$
\begin{aligned}
& x_{m j}=\left(m_{i j}-l_{i}^{\min }\right) / \Delta_{\text {min }}^{\max } \\
& x_{u j}=\left(u_{i j}-l_{i}^{\min }\right) / \Delta_{\text {min }}^{\max }
\end{aligned}
$$

(ii) Compute left (ls) and right (rs) normalized values, for $j=1, \ldots, J$

$x_{j}^{l s}=x_{m j} /\left(1+x_{m j}-x_{l j}\right)$

$x_{j}^{r s}=x_{u j} /\left(1+x_{u j}-x_{m j}\right)$

(iii) Compute total normalized crisp value, for $j=1, \ldots, J$ $x_{j}^{c}=\left[x_{j}^{l s}\left(1-x_{j}^{l s}\right)+x_{j}^{r s} \cdot x_{j}^{r s}\right] /\left[1-x_{j}^{l s}+x_{j}^{r s}\right](28)$

(iv) Compute crisp values, for $j=1, \ldots, J$

$$
f_{i j}=l_{i}^{\min }+x_{j}^{c} \cdot \Delta_{\min }^{\max }
$$

This four step CFCS procedure is performed for all criteria $\tilde{f}_{i}, i \in n$, where $\tilde{n}$ denotes the set of criteria evaluated with fuzzy numbers. All values $\tilde{f}_{i j}=$ $\left(l_{i j}, m_{i j}, u_{i j}\right) j=1, \ldots, J$, of the i-th (one) criterion are included in the computation, even if not all alternatives are evaluated with fuzzy numbers (some of these values could be crisp, $1=\mathrm{m}=\mathrm{u})^{77}$.

For all risks, Equations (23-29) should be implemented separately.

\section{An Application of the Proposed Model}

The case study for the application of proposed model is performed in a public institution which applies strategic management model. For the application, a team is established from four experts of institution and one of the authors of this paper. Institutional experts assigned from risk assessment and strategic planning departments. The public institution has a strategic plan and also has strategic goals and objectives. First level criteria (strategic goals) and second level criteria 
(strategic objectives) to be used in the model were selected from this strategic plan and the risks were identified by the team. Comparison matrices used to calculate local and global weights were also formed by the same team. The application performed based on the steps provided in previous section and explained step by step together with the results.
Step 1: The first and second level criteria used to prioritize the risks are determined in this step is shown in Table 2.

Step 2: The AHP model formed by the criteria and alternatives determined in the first step is shown in Figure 1.

Table 2. Criteria and alternatives used in the model

\begin{tabular}{|c|c|}
\hline $\begin{array}{l}\text { 1st level criteria } \\
\text { (Strategic } \\
\text { Objectives) }\end{array}$ & $\begin{array}{l}\text { SO1 Ensure effective alignment with EU acquis communautaire and effective utilization of EU funds } \\
\text { SO2 Make R\&D and innovation an integral part of the organizational culture } \\
\text { SO3 Improve human resources management } \\
\text { SO4 Develop a culture of continuous performance improvement } \\
\text { SO5 Upgrade information technology governance to the level of international best practices }\end{array}$ \\
\hline $\begin{array}{l}\text { 2nd level criteria } \\
\text { (Activities) }\end{array}$ & $\begin{array}{l}\text { A1 Complete activities for which the Treasury is responsible in alignment with the EU acquis } \\
\text { A2 Improve Human Resources Management (Transform existing procedures and principles related to } \\
\text { appointments, orientation, posting, awards, promotion, internships, performance evaluation and rotation } \\
\text { into internal regulation. ) } \\
\text { A3 Increase arrangements for internships, seminars, conferences and courses in order to ensure aggregate } \\
\text { expansion in professional expertise } \\
\text { A4 Upgrade the internal control system and standards to the level of international best practice, including } \\
\text { such standards as those promoted by COSO (Committee of Sponsoring Organizations of the Treadway } \\
\text { Commission) and INTOSAI (International Organization of Supreme Audit Institutions) } \\
\text { A5 Integrate decision support mechanisms, occupational intelligence and internet technologies solutions } \\
\text { into information systems } \\
\text { A6 Prepare audit guides and create internal quality assurance and development programs }\end{array}$ \\
\hline $\begin{array}{l}\text { Alternatives } \\
\text { (Risks) }\end{array}$ & $\begin{array}{l}\text { R1 Internal control system } \\
\text { R2 Human resources management } \\
\text { R3 Organizational, institutional, managerial or corporate cultural } \\
\text { R4 Task distribution and delegation of authority } \\
\text { R5 Integration of business objectives and information technologies } \\
\text { R6 Risk management system (identifying, analyzing, addressing and monitoring risks) } \\
\text { R7 EU membership process }\end{array}$ \\
\hline
\end{tabular}

AHP model is composed of four levels. The first step includes the objective of the model, determined as "prioritization of risks". The second step includes the strategic objectives as first level criteria to be used in the prioritization of risks. Activities related to the strategic objectives are in the third level and risks (alternatives) are in the last level of the model.
Step 3: The first task of the work team is to decide on the relative importance of the five strategic objectives. Through pairwise comparison, a triangular fuzzy comparison matrix is constructed and shown in Table 3. Non-linear model which provided from this matrix and its solution are annexed (Appendix A). 
Fig. 1. Hierarchical structure for the prioritization of risks

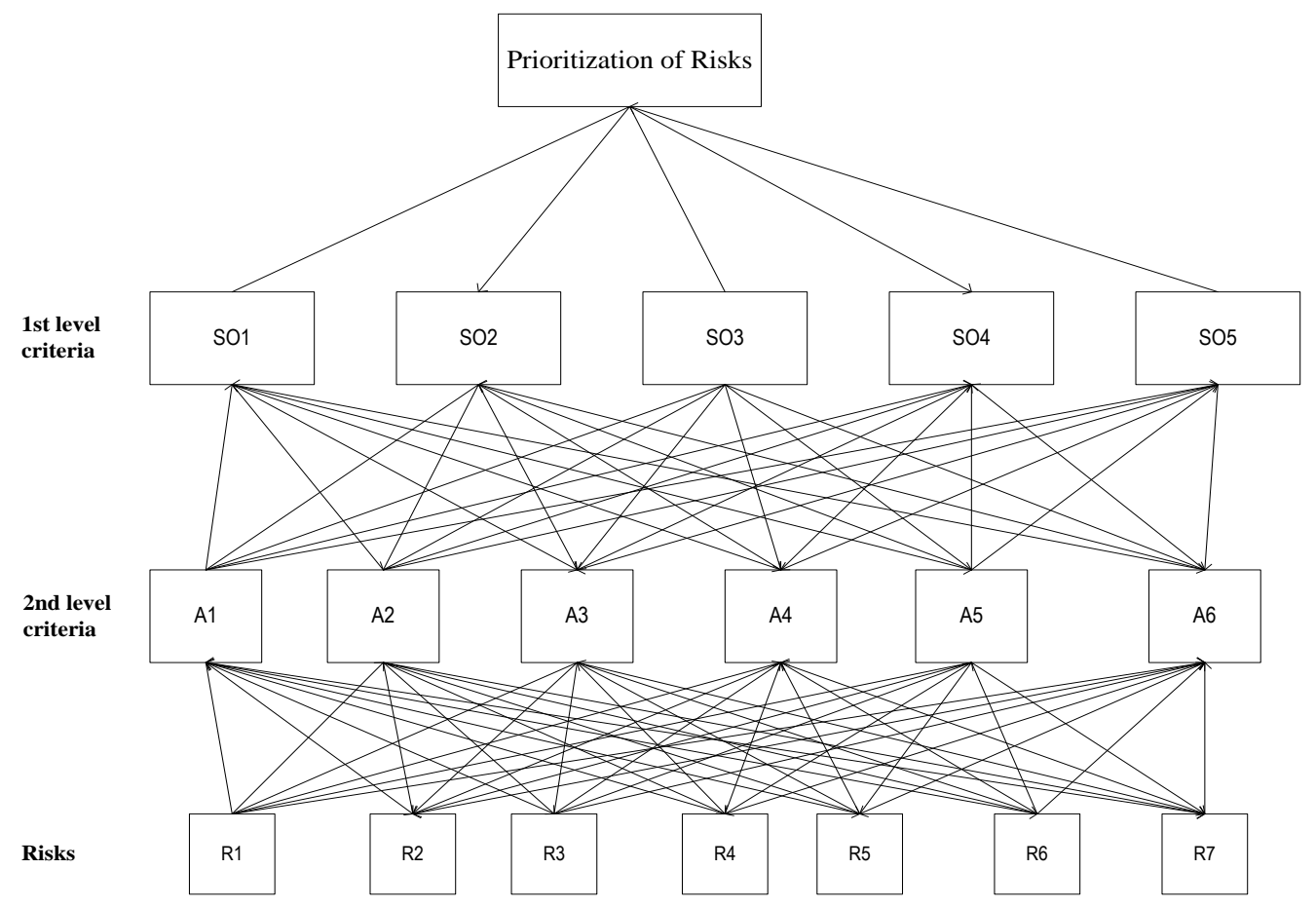

Table 3: Fuzzy comparison matrix of the five strategic objectives with respect to the objective

\begin{tabular}{c|ccccc} 
SOs & SO1 & SO2 & SO3 & SO4 & SO5 \\
SO1 & $(1,1,1)$ & $(1,1,1)$ & $(2 / 3,1,2)$ & $(2 / 3,1,2)$ & $(1 / 2,2 / 3,1)$ \\
SO2 & $(1,1,1)$ & $(1,1,1)$ & $(2 / 3,1,2)$ & $(1 / 2,2 / 3,1)$ & $(1 / 2,2 / 3,1)$ \\
SO3 & $(1 / 2,1,3 / 2)$ & $(1 / 2,1,3 / 2)$ & $(1,1,1)$ & $(1 / 2,1,3 / 2)$ & $(2 / 3,1,2)$ \\
SO4 & $(1 / 2,1,3 / 2)$ & $(1,3 / 2,2)$ & $(2 / 3,1,2)$ & $(1,1,1)$ & $(1,3 / 2,2)$ \\
SO5 & $(1,3 / 2,2)$ & $(1,3 / 2,2)$ & $(1 / 2,1,3 / 2)$ & $(1 / 2,2 / 3,1)$ & $(1,1,1)$ \\
\hline
\end{tabular}

Step 4: Team members compare the activities under each of the five strategic objectives separately. Table 4 shows their comparisons under each strategic objective, which form five triangular fuzzy comparison matrices, respectively.

Step 5-6 : The local fuzzy weights for the fuzzy comparison matrices can be obtained by solving model (19) for each of the comparison matrices. Table 5 shows the results. GAMS optimization software package used as solver and a sample model and its solution are annexed (Appendix A). The results obtained from this sample solution of Table 3 used as first row of Table 5. Other values in column based provided by same method from fuzzy comparison matrices of activities with respect to the each strategic objective (Table 4). Similarly, the global fuzzy weights of the six activities are determined by Eqs. (20)-(22) and used in Table 7 as global weights of activities.

Values of Table 7 in column based provided by GAMS from fuzzy comparison matrices of risks with respect to each activity (Table 6). Additionally the results obtained from Table 5 used as first row of Table 7. 
Table 4. Fuzzy comparison of activities with respect to the each strategic objective

\begin{tabular}{|c|c|c|c|c|c|c|}
\hline & A1 & A2 & A3 & A4 & A5 & A6 \\
\hline \multicolumn{7}{|c|}{ Fuzzy comparison matrix of the activities with respect to the strategic objective 1} \\
\hline A1 & $(1,1,1)$ & $(2,5 / 2,3)$ & $(2,5 / 2,3)$ & $(1,3 / 2,2)$ & $(3 / 2,2,5 / 2)$ & $(1,3 / 2,2)$ \\
\hline A2 & $(1 / 3,2 / 5,1 / 2)$ & $(1,1,1)$ & $(2 / 3,1,2)$ & $(2 / 5,1 / 2,2 / 3)$ & $(1 / 2,2 / 3,1)$ & $(2 / 5,1 / 2,2 / 3)$ \\
\hline A3 & $(1 / 3,2 / 5,1 / 2)$ & $(1 / 2,1,3 / 2)$ & $(1,1,1)$ & $(2 / 5,1 / 2,2 / 3)$ & $(2 / 3,1,2)$ & $(2 / 5,1 / 2,2 / 3)$ \\
\hline A4 & $(1 / 2,2 / 3,1)$ & $(3 / 2,2,5 / 2)$ & $(3 / 2,2,5 / 2)$ & $(1,1,1)$ & $(1,3 / 2,2)$ & $(1 / 2,1,3 / 2)$ \\
\hline A5 & $(2 / 5,1 / 2,2 / 3)$ & $(1,3 / 2,2)$ & $(1 / 2,1,3 / 2)$ & $(1 / 2,2 / 3,1)$ & $(1,1,1)$ & $(1 / 2,2 / 3,1)$ \\
\hline A6 & $(1 / 2,2 / 3,1)$ & $(3 / 2,2,5 / 2)$ & $(3 / 2,2,5 / 2)$ & $(2 / 3,1,2)$ & $(1,3 / 2,2)$ & $(1,1,1)$ \\
\hline \multicolumn{7}{|c|}{ Fuzzy comparison matrix of the activities with respect to the strategic objective 2} \\
\hline A1 & $(1,1,1)$ & $(2 / 5,1 / 2,2 / 3)$ & $(2 / 5,1 / 2,2 / 3)$ & $(1 / 2,2 / 3,1)$ & $(1 / 2,2 / 3,1)$ & $(1 / 2,2 / 3,1)$ \\
\hline A2 & $(3 / 2,2,5 / 2)$ & $(1,1,1)$ & $(1 / 2,1,3 / 2)$ & $(1,3 / 2,2)$ & $(1 / 2,1,3 / 2)$ & $(1,3 / 2,2)$ \\
\hline A3 & $(3 / 2,2,5 / 2)$ & $(2 / 3,1,2)$ & $(1,1,1)$ & $(1,3 / 2,2)$ & $(1 / 2,1,3 / 2)$ & $(1,3 / 2,2)$ \\
\hline A4 & $(1,3 / 2,2)$ & $(1 / 2,2 / 3,1)$ & $(1 / 2,2 / 3,1)$ & $(1,1,1)$ & $(2 / 3,1,2)$ & $(1 / 2,1,3 / 2)$ \\
\hline A5 & $(1,3 / 2,2)$ & $(2 / 3,1,2)$ & $(2 / 3,1,2)$ & $(1 / 2,1,3 / 2)$ & $(1,1,1)$ & $(1 / 2,1,3 / 2)$ \\
\hline A6 & $(1,3 / 2,2)$ & $(1 / 2,2 / 3,1)$ & $(1 / 2,2 / 3,1)$ & $(2 / 3,1,2)$ & $(2 / 3,1,2)$ & $(1,1,1)$ \\
\hline \multicolumn{7}{|c|}{ Fuzzy comparison matrix of the activities with respect to the strategic objective 3} \\
\hline A1 & $(1,1,1)$ & $(2 / 7,1 / 3,2 / 5)$ & $(1 / 3,2 / 5,1 / 2)$ & $(1 / 2,2 / 3,1)$ & $(1 / 2,1,3 / 2)$ & $(1,3 / 2$ \\
\hline A2 & $(5 / 2,3,7 / 2)$ & $(1,1,1)$ & $(1,3 / 2,2)$ & $(3 / 2,2,5 / 2)$ & $(2,5 / 2,3)$ & $(5 / 2,3,7 / 2)$ \\
\hline A3 & $(2,5 / 2,3)$ & $(1 / 2,2 / 3,1)$ & $(1,1,1)$ & $(1,3 / 2,2)$ & $(3 / 2,2,5 / 2)$ & $(2,5 / 2,3)$ \\
\hline A4 & $(1,3 / 2,2)$ & $(2 / 5,1 / 2,2 / 3)$ & $(1 / 2,2 / 3,1)$ & $(1,1,1)$ & $(1,3 / 2,2)$ & $(3 / 2,2,5 / 2)$ \\
\hline A5 & $(2 / 3,1,2)$ & $(1 / 3,2 / 5,1 / 2)$ & $(2 / 5,1 / 2,2 / 3)$ & $(1 / 2,2 / 3,1)$ & $(1,1,1)$ & $(1,3 / 2,2)$ \\
\hline A6 & $(1 / 2,2 / 3,1)$ & $(2 / 7,1 / 3,2 / 5)$ & $(1 / 3,2 / 5,1 / 2)$ & $(2 / 5,1 / 2,2 / 3)$ & $(1 / 2,2 / 3,1)$ & $(1,1,1)$ \\
\hline \multicolumn{7}{|c|}{ Fuzzy comparison matrix of the activities with respect to the strategic objective 4} \\
\hline A1 & $(1,1,1)$ & $(1 / 2,2 / 3,1)$ & $(2 / 5,1 / 2,2 / 3)$ & $(1 / 3,2 / 5,1 / 2)$ & $(1 / 3,2 / 5,1 / 2)$ & $(1 / 2,2 / 3,1)$ \\
\hline A2 & $(1,3 / 2,2)$ & $(1,1,1)$ & $(1 / 2,2 / 3,1)$ & $(2 / 5,1 / 2,2 / 3)$ & $(2 / 5,1 / 2,2 / 3)$ & $(1 / 2,1,3 / 2)$ \\
\hline A3 & $(3 / 2,2,5 / 2)$ & $(1,3 / 2,2)$ & $(1,1,1)$ & $(1 / 2,2 / 3,1)$ & $(1 / 2,2 / 3,1)$ & $(1,3 / 2,2)$ \\
\hline A4 & $(2,5 / 2,3)$ & $(3 / 2,2,5 / 2)$ & $(1,3 / 2,2)$ & $(1,1,1)$ & $(1 / 2,1,3 / 2)$ & $(3 / 2,2,5 / 2)$ \\
\hline A5 & $(2,5 / 2,3)$ & $(3 / 2,2,5 / 2)$ & $(1,3 / 2,2)$ & $(2 / 3,1,2)$ & $(1,1,1)$ & $(3 / 2,2,5 / 2)$ \\
\hline A6 & $(1,3 / 2,2)$ & $(2 / 3,1,2)$ & $(1 / 2,2 / 3,1)$ & $(2 / 5,1 / 2,2 / 3)$ & $(2 / 5,1 / 2,2 / 3)$ & $(1,1,1)$ \\
\hline \multicolumn{7}{|c|}{ Fuzzy comparison matrix of the activities with respect to the strategic objective 5} \\
\hline A1 & $(1,1,1)$ & $(1 / 2,2 / 3,1)$ & $(1 / 2,2 / 3,1)$ & $(2 / 5,1 / 2,2 / 3)$ & $(1 / 3,2 / 5,1 / 2)$ & $(2 / 3,1,2)$ \\
\hline A2 & $(1,3 / 2,2)$ & $(1,1,1)$ & $(1 / 2,1,3 / 2)$ & $(1 / 2,2 / 3,1)$ & $(1 / 2,2 / 3,1)$ & $(1,3 / 2,2)$ \\
\hline A3 & $(1,3 / 2,2)$ & $(2 / 3,1,2)$ & $(1,1,1)$ & $(2 / 3,1,2)$ & $(2 / 5,1 / 2,2 / 3)$ & $(1 / 2,1,3 / 2)$ \\
\hline A4 & $(3 / 2,2,5 / 2)$ & $(1,3 / 2,2)$ & $(1 / 2,1,3 / 2)$ & $(1,1,1)$ & $(2 / 3,1,2)$ & $(3 / 2,2,5 / 2)$ \\
\hline A5 & $(2,5 / 2,3)$ & $(1,3 / 2,2)$ & $(3 / 2,2,5 / 2)$ & $(1 / 2,1,3 / 2)$ & $(1,1,1)$ & $(2,5 / 2,3)$ \\
\hline A6 & $(1 / 2,1,3 / 2)$ & $(1 / 2,2 / 3,1)$ & $(2 / 3,1,2)$ & $(2 / 5,1 / 2,2 / 3)$ & $(1 / 3,2 / 5,1 / 2)$ & $(1,1,1)$ \\
\hline
\end{tabular}

Table 5. Local and global fuzzy weights of the activities obtained by the modified fuzzy LLSM

\begin{tabular}{|c|c|c|c|c|c|c|}
\hline \multirow{2}{*}{ 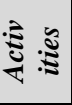 } & SO1 & SO2 & SO3 & SO4 & SO5 & \multirow{2}{*}{$\begin{array}{c}\text { Global Fuzzy } \\
\text { Weights }\end{array}$} \\
\hline & $(0.193,0.193,0.213)$ & $(0.163,0.168,0.186)$ & $(0.123,0.197,0.245)$ & $(0.154,0.213,0.268)$ & $(0.161,0.230,0.294)$ & \\
\hline$A 1$ & $(0.240,0.272,0.286)$ & $(0.100,0.105,0.116)$ & $(0.087,0.107,0.127)$ & $(0.083,0.089,0.101)$ & $(0.096,0.106,0.127)$ & $(0.102,0.135,0.178)$ \\
\hline$A 2$ & $(0.089,0.099,0.120)$ & $(0.156,0.209,0.233)$ & $(0.276,0.304,0.316)$ & $(0.100,0.124,0.147)$ & $(0.125,0.159,0.187)$ & $(0.112,0.177,0.241)$ \\
\hline$A 3$ & $(0.088,0.106,0.131)$ & $(0.164,0.209,0.244)$ & $(0.200,0.229,0.255)$ & $(0.146,0.175,0.204)$ & $(0.115,0.151,0.202)$ & $(0.109,0.173,0.249)$ \\
\hline$A 4$ & $(0.157,0.196,0.227)$ & $(0.120,0.152,0.188)$ & $(0.134,0.161,0.189)$ & $(0.197,0.244,0.271)$ & $(0.169,0.214,0.255)$ & $(0.124,0.196,0.277)$ \\
\hline$A 5$ & $(0.104,0.130,0.157)$ & $(0.122,0.174,0.233)$ & $(0.096,0.115,0.146)$ & $(0.207,0.244,0.285)$ & $(0.219,0.254,0.272)$ & $(0.119,0.187,0.269)$ \\
\hline$A 6$ & $(0.164,0.197,0.238)$ & $(0.126,0.152,0.197)$ & $(0.077,0.084,0.096)$ & $(0.105,0.124,0.155)$ & $(0.094,0.116,0.139)$ & $(0.093,0.133,0.193)$ \\
\hline
\end{tabular}


Table 6. Fuzzy comparison of risks with respect to each activity

\begin{tabular}{|c|c|c|c|c|c|c|c|}
\hline & $\mathbf{R 1}$ & $\mathbf{R 2}$ & $\mathbf{R 3}$ & $\mathbf{R 4}$ & $\mathbf{R 5}$ & R6 & R7 \\
\hline \multicolumn{8}{|c|}{ Fuzzy comparison matrix of the risks with respect to the activity 1} \\
\hline $\mathbf{R 1}$ & $(1,1,1)$ & $(1,3 / 2,2)$ & $(3 / 2,2,5 / 2)$ & $(3 / 2,2,5 / 2)$ & $(1,3 / 2,2)$ & $(1 / 2,1,3 / 2)$ & $(1 / 2,2 / 3,1)$ \\
\hline $\mathbf{R 2}$ & $(1 / 2,2 / 3,1)$ & $(1,1,1)$ & $(1,3 / 2,2)$ & $(1,3 / 2,2)$ & $(1,1,1)$ & $(1 / 2,2 / 3,1)$ & $(2 / 5,1 / 2,2 / 3)$ \\
\hline $\mathbf{R 3}$ & $(2 / 5,1 / 2,2 / 3)$ & $(1 / 2,2 / 3,1)$ & $(1,1,1)$ & $(2 / 3,1,2)$ & $(1 / 2,2 / 3,1)$ & $(2 / 5,1 / 2,2 / 3)$ & $(1 / 3,2 / 5,1 / 2)$ \\
\hline $\mathbf{R 4}$ & $(2 / 5,1 / 2,2 / 3)$ & $(1 / 2,2 / 3,1)$ & $(1 / 2,1,3 / 2)$ & $(1,1,1)$ & $(1 / 2,2 / 3,1)$ & $(2 / 5,1 / 2,2 / 3)$ & $(1 / 3,2 / 5,1 / 2)$ \\
\hline R5 & $(1 / 2,2 / 3,1)$ & $(1,1,1)$ & $(1,3 / 2,2)$ & $(1,3 / 2,2)$ & $(1,1,1)$ & $(1 / 2,2 / 3,1)$ & $(2 / 5,1 / 2,2 / 3)$ \\
\hline R6 & $(2 / 3,1,2)$ & $(1,3 / 2,2)$ & $(3 / 2,2,5 / 2)$ & $(3 / 2,2,5 / 2)$ & $(1,3 / 2,2)$ & $(1,1,1)$ & $(1 / 2,2 / 3,1)$ \\
\hline R7 & $(1,3 / 2,2)$ & $(3 / 2,2,5 / 2)$ & $(2,5 / 2,3)$ & $(2,5 / 2,3)$ & $(3 / 2,2,5 / 2)$ & $(1,3 / 2,2)$ & $(1,1,1)$ \\
\hline \multicolumn{8}{|c|}{ Fuzzy comparison matrix of the risks with respect to the activity 2} \\
\hline $\mathbf{R 1}$ & $(1,1,1)$ & $(1,3 / 2,2)$ & $(1 / 2,2 / 3,1)$ & $(1,3 / 2,2)$ & $(2 / 3,1,2)$ & $(1 / 2,1,3 / 2)$ & $(1,3 / 2,2)$ \\
\hline $\mathbf{R 2}$ & $(1 / 2,2 / 3,1)$ & $(1,1,1)$ & $(2 / 5,1 / 2,2 / 3)$ & $(1,3 / 2,2)$ & $(1 / 2,2 / 3,1)$ & $(2 / 3,1,2)$ & $(1 / 2,1,3 / 2)$ \\
\hline $\mathbf{R 3}$ & $(1,3 / 2,2)$ & $(3 / 2,2,5 / 2)$ & $(1,1,1)$ & $(3 / 2,2,5 / 2)$ & $(1 / 2,1,3 / 2)$ & $(1,3 / 2,2)$ & $(3 / 2,2,5 / 2)$ \\
\hline $\mathbf{R 4}$ & $(1 / 2,2 / 3,1)$ & $(1 / 2,2 / 3,1)$ & $(2 / 5,1 / 2,2 / 3)$ & $(1,1,1)$ & $(2 / 5,1 / 2,2 / 3)$ & $(1 / 2,2 / 3,1)$ & $(2 / 3,1,2)$ \\
\hline R5 & $(1 / 2,1,3 / 2)$ & $(1,3 / 2,2)$ & $(2 / 3,1,2)$ & $(3 / 2,2,5 / 2)$ & $(1,1,1)$ & $(1 / 2,1,3 / 2)$ & $(3 / 2,2,5 / 2)$ \\
\hline R6 & $(2 / 3,1,2)$ & $(1 / 2,1,3 / 2)$ & $(1 / 2,2 / 3,1)$ & $(1,3 / 2,2)$ & $(2 / 3,1,2)$ & $(1,1,1)$ & $(1 / 2,1,3 / 2)$ \\
\hline R7 & $(1 / 2,2 / 3,1)$ & $(2 / 3,1,2)$ & $(2 / 5,1 / 2,2 / 3)$ & $(1 / 2,1,3 / 2)$ & $(2 / 5,1 / 2,2 / 3)$ & $(2 / 3,1,2)$ & $(1,1,1)$ \\
\hline \multicolumn{8}{|c|}{ Fuzzy comparison matrix of the risks with respect to the activity 3} \\
\hline $\mathbf{R 1}$ & $(1,1,1)$ & $(1 / 3,2 / 5,1 / 2)$ & $(1 / 2,2 / 3,1)$ & $(2 / 5,1 / 2,2 / 3)$ & $(2 / 3,1,2)$ & $(2 / 5,1 / 2,2 / 3)$ & $(1 / 2,2 / 3,1)$ \\
\hline $\mathbf{R 2}$ & $(2,5 / 2,3)$ & $(1,1,1)$ & $(3 / 2,2,5 / 2)$ & $(1,3 / 2,2)$ & $(2,5 / 2,3)$ & $(1,3 / 2,2)$ & $(3 / 2,2,5 / 2)$ \\
\hline $\mathbf{R 3}$ & $(1,3 / 2,2)$ & $(2 / 5,1 / 2,2 / 3)$ & $(1,1,1)$ & $(1 / 2,2 / 3,1)$ & $(1,3 / 2,2)$ & $(1 / 2,2 / 3,1)$ & $(2 / 3,1,2)$ \\
\hline R4 & $(3 / 2,2,5 / 2)$ & $(1 / 2,2 / 3,1)$ & $(1,3 / 2,2)$ & $(1,1,1)$ & $(3 / 2,2,5 / 2)$ & $(1 / 2,1,3 / 2)$ & $(1,3 / 2,2)$ \\
\hline $\mathbf{R 5}$ & $(1 / 2,1,3 / 2)$ & $(1 / 3,2 / 5,1 / 2)$ & $(1 / 2,2 / 3,1)$ & $(2 / 5,1 / 2,2 / 3)$ & $(1,1,1)$ & $(2 / 5,1 / 2,2 / 3)$ & $(1 / 2,2 / 3,1)$ \\
\hline R6 & $(3 / 2,2,5 / 2)$ & $(1 / 2,2 / 3,1)$ & $(1,3 / 2,2)$ & $(2 / 3,1,2)$ & $(3 / 2,2,5 / 2)$ & $(1,1,1)$ & $(1,3 / 2,2)$ \\
\hline R7 & $(1,3 / 2,2)$ & $(2 / 5,1 / 2,2 / 3)$ & $(1 / 2,1,3 / 2)$ & $(1 / 2,2 / 3,1)$ & $(1,3 / 2,2)$ & $(1 / 2,2 / 3,1)$ & $(1,1,1)$ \\
\hline \multicolumn{8}{|c|}{ Fuzzy comparison matrix of the risks with respect to the activity 4} \\
\hline R1 & $(1,1,1)$ & $(2 / 3,1,2)$ & $(1,3 / 2,2)$ & $(1 / 2,2 / 3,1)$ & $(1 / 2,2 / 3,1)$ & $(1,3 / 2,2)$ & $(2,5 / 2,3)$ \\
\hline $\mathbf{R 2}$ & $(1 / 2,1,3 / 2)$ & $(1,1,1)$ & $(1,3 / 2,2)$ & $(1 / 2,2 / 3,1)$ & $(1 / 2,2 / 3,1)$ & $(1,3 / 2,2)$ & $(2,5 / 2,3)$ \\
\hline $\mathbf{R 3}$ & $(1 / 2,2 / 3,1)$ & $(1 / 2,2 / 3,1)$ & $(1,1,1)$ & $(2 / 5,1 / 2,2 / 3)$ & $(2 / 5,1 / 2,2 / 3)$ & $(1 / 2,1,3 / 2)$ & $(3 / 2,2,5 / 2)$ \\
\hline R4 & $(1,3 / 2,2)$ & $(1,3 / 2,2)$ & $(3 / 2,2,5 / 2)$ & $(1,1,1)$ & $(1 / 2,1,3 / 2)$ & $(3 / 2,2,5 / 2)$ & $(5 / 2,3,7 / 2)$ \\
\hline R5 & $(1,3 / 2,2)$ & $(1,3 / 2,2)$ & $(3 / 2,2,5 / 2)$ & $(2 / 3,1,2)$ & $(1,1,1)$ & $(3 / 2,2,5 / 2)$ & $(5 / 2,3,7 / 2)$ \\
\hline R6 & $(1 / 2,2 / 3,1)$ & $(1 / 2,2 / 3,1)$ & $(2 / 3,1,2)$ & $(2 / 5,1 / 2,2 / 3)$ & $(2 / 5,1 / 2,2 / 3)$ & $(1,1,1)$ & $(3 / 2,2,5 / 2)$ \\
\hline R7 & $(1 / 3,2 / 5,1 / 2)$ & $(1 / 3,2 / 5,1 / 2)$ & $(2 / 5,1 / 2,2 / 3)$ & $(2 / 7,1 / 3,2 / 5)$ & $(2 / 7,1 / 3,2 / 5)$ & $(2 / 5,1 / 2,2 / 3)$ & $(1,1,1)$ \\
\hline \multicolumn{8}{|c|}{ Fuzzy comparison matrix of the risks with respect to the activity 5} \\
\hline $\mathbf{R 1}$ & $(1,1,1)$ & $(3 / 2,2,5 / 2)$ & $(1 / 2,1,3 / 2)$ & $(3 / 2,2,5 / 2)$ & $(2 / 3,1,2)$ & $(1,3 / 2,2)$ & $(1,3 / 2,2)$ \\
\hline $\mathbf{R 2}$ & $(2 / 5,1 / 2,2 / 3)$ & $(1,1,1)$ & $(2 / 5,1 / 2,2 / 3)$ & $(2 / 3,1,2)$ & $(1 / 3,2 / 5,1 / 2)$ & $(1 / 2,2 / 3,1)$ & $(1 / 2,2 / 3,1)$ \\
\hline $\mathbf{R 3}$ & $(2 / 3,1,2)$ & $(3 / 2,2,5 / 2)$ & $(1,1,1)$ & $(3 / 2,2,5 / 2)$ & $(1 / 2,2 / 3,1)$ & $(1 / 2,1,3 / 2)$ & $(1,3 / 2,2)$ \\
\hline $\mathbf{R 4}$ & $(2 / 5,1 / 2,2 / 3)$ & $(1 / 2,1,3 / 2)$ & $(2 / 5,1 / 2,2 / 3)$ & $(1,1,1)$ & $(1 / 3,2 / 5,1 / 2)$ & $(1 / 2,2 / 3,1)$ & $(1 / 2,2 / 3,1)$ \\
\hline R5 & $(1 / 2,1,3 / 2)$ & $(2,5 / 2,3)$ & $(1,3 / 2,2)$ & $(2,5 / 2,3)$ & $(1,1,1)$ & $(3 / 2,2,5 / 2)$ & $(3 / 2,2,5 / 2)$ \\
\hline R6 & $(1 / 2,2 / 3,1)$ & $(1,3 / 2,2)$ & $(2 / 3,1,2)$ & $(1,3 / 2,2)$ & $(2 / 5,1 / 2,2 / 3)$ & $(1,1,1)$ & $(1 / 2,1,3 / 2)$ \\
\hline R7 & $(1 / 2,2 / 3,1)$ & $(1,3 / 2,2)$ & $(1 / 2,2 / 3,1)$ & $(1,3 / 2,2)$ & $(2 / 5,1 / 2,2 / 3)$ & $(2 / 3,1,2)$ & $(1,1,1)$ \\
\hline \multicolumn{8}{|c|}{ Fuzzy comparison matrix of the risks with respect to the activity 6} \\
\hline $\mathbf{R 1}$ & $(1,1,1)$ & $(5 / 2,3,7 / 2)$ & $(2,5 / 2,3)$ & $(2,5 / 2,3)$ & $(3 / 2,2,5 / 2)$ & $(1,3 / 2,2)$ & $(1 / 2,1,3 / 2)$ \\
\hline $\mathbf{R 2}$ & $(2 / 7,1 / 3,2 / 5)$ & $(1,1,1)$ & $(1 / 2,2 / 3,1)$ & $(1 / 2,2 / 3,1)$ & $(2 / 5,1 / 2,2 / 3)$ & $(1 / 3,2 / 5,1 / 2)$ & $(2 / 5,1 / 2,2 / 3)$ \\
\hline $\mathbf{R 3}$ & $(1 / 3,2 / 5,1 / 2)$ & $(1,3 / 2,2)$ & $(1,1,1)$ & $(2 / 3,1,2)$ & $(1 / 2,2 / 3,1)$ & $(2 / 5,1 / 2,2 / 3)$ & $(1 / 2,2 / 3,1)$ \\
\hline R4 & $(1 / 3,2 / 5,1 / 2)$ & $(1,3 / 2,2)$ & $(1 / 2,1,3 / 2)$ & $(1,1,1)$ & $(1 / 2,2 / 3,1)$ & $(2 / 5,1 / 2,2 / 3)$ & $(1 / 2,2 / 3,1)$ \\
\hline R5 & $(2 / 5,1 / 2,2 / 3)$ & $(3 / 2,2,5 / 2)$ & $(1,3 / 2,2)$ & $(1,3 / 2,2)$ & $(1,1,1)$ & $(1 / 2,2 / 3,1)$ & $(2 / 3,1,2)$ \\
\hline R6 & $(1 / 2,2 / 3,1)$ & $(2,5 / 2,3)$ & $(3 / 2,2,5 / 2)$ & $(3 / 2,2,5 / 2)$ & $(1,3 / 2,2)$ & $(1,1,1)$ & $(1 / 2,1,3 / 2)$ \\
\hline R7 & $(2 / 3,1,2)$ & $(3 / 2,2,5 / 2)$ & $(1,3 / 2,2)$ & $(1,3 / 2,2)$ & $(1 / 2,1,3 / 2)$ & $(2 / 3,1,2)$ & $(1,1,1)$ \\
\hline
\end{tabular}


Step 7: Team members compare the risks under each of the six alternatives separately. Table 6 shows their comparisons under each alternative, which form six triangular fuzzy comparison matrices, respectively.

Step 8: The local fuzzy weights for the six fuzzy comparison matrices can be obtained by solving model
(19) for each of them. Table 7 shows the results. The global fuzzy weights of the seven risks are determined by Eqs. (20)-(22) and shown in Fig. 2. It is clear that Risk 1 is the most prior risk according to proposed model and Risk 5 has the nearest value to it.

Table 7. Local and global fuzzy weights of the risks obtained by the modified fuzzy LLSM

\begin{tabular}{|c|c|c|c|c|c|c|c|}
\hline \multirow{2}{*}{$\frac{n}{\grave{n}}$} & $\mathbf{A 1}$ & $\mathbf{A 2}$ & A3 & A4 & A5 & A6 & \multirow{2}{*}{$\begin{array}{c}\text { Global Fuzzy } \\
\text { Weights }\end{array}$} \\
\hline & $(0.102,0.135,0.178)$ & $(0.112,0.177,0.241)$ & $(0.109,0.173,0.249)$ & $(0.124,0.196,0.277)$ & $(0.119,0.187,0.269)$ & $(0.093,0.133,0.193)$ & \\
\hline$R \boldsymbol{R}$ & $(0.139,0.183,0.215)$ & $(0.117,0.155,0.215)$ & $(0.077,0.077,0.102)$ & $(0.124,0.151,0.187)$ & $(0.137,0.193,0.280)$ & $(0.204,0.237,0.261)$ & $(0.086,0.163,0.293)$ \\
\hline$R 2$ & $(0.111,0.127,0.142)$ & $(0.097,0.118,0.141)$ & $(0.188,0.188,0.188)$ & $(0.119,0.151,0.179)$ & $(0.078,0.089,0.102)$ & $(0.069,0.073,0.083)$ & $(0.073,0.126,0.199)$ \\
\hline$R 3$ & $(0.077,0.089,0.111)$ & $(0.172,0.208,0.215)$ & $(0.102,0.130,0.147)$ & $(0.089,0.107,0.127)$ & $(0.130,0.171,0.200)$ & $(0.086,0.100,0.125)$ & $(0.073,0.138,0.221)$ \\
\hline$R 4$ & $(0.073,0.089,0.106)$ & $(0.086,0.095,0.112)$ & $(0.128,0.192,0.313)$ & $(0.170,0.212,0.235)$ & $(0.075,0.089,0.098)$ & $(0.083,0.100, .0120)$ & $(0.069,0.134,0.239)$ \\
\hline$R 5$ & $(0.111,0.127,0.142)$ & $(0.135,0.178,0.206)$ & $(0.074,0.091,0.098)$ & $(0.177,0.212,0.245)$ & $(0.195,0.199,0.199)$ & $(0.118,0.141,0.176)$ & $(0.091,0.162,0.255)$ \\
\hline$R 6$ & $(0.145,0.183,0.224)$ & $(0.102,0.138,0.180)$ & $(0.144,0.192,0.201)$ & $(0.092,0.107,0.132)$ & $(0.099,0.134,0.158)$ & $(0.153,0.185,0.215)$ & $(0.079,0.153,0.254)$ \\
\hline$R 7$ & $(0.202,0.202,0.202)$ & $(0.088,0.107,0.134)$ & $(0.097,0.130,0.141)$ & $(0.060,0.061,0.063)$ & $(0.102,0.126,0.147)$ & $(0.128,0.165,0.181)$ & $(0.072,0.126,0.195)$ \\
\hline
\end{tabular}

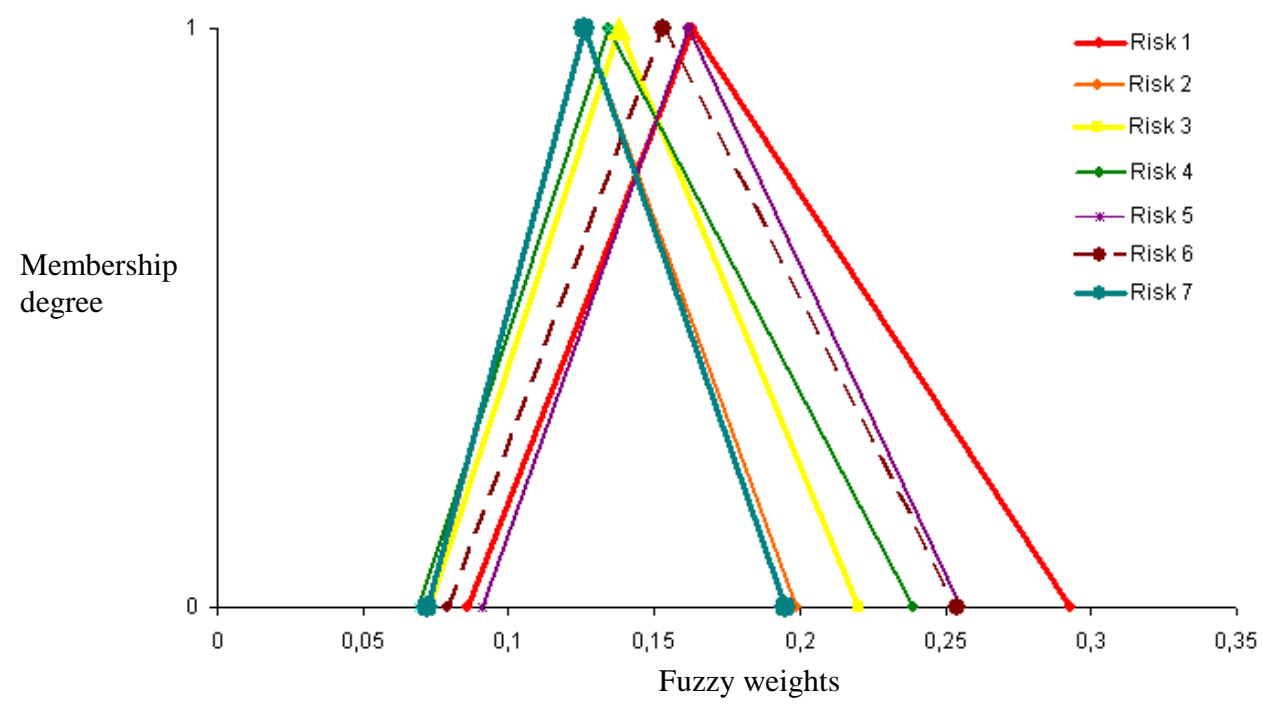

Figure 2. Global fuzzy weights of the risks obtained by the modified fuzzy LLSM

Step 9: After calculating global fuzzy weights, this study adopted the CSCF method $^{77}$ to undertake defuzzification. Eqs. (23)-(29) are adopted to obtain crisp judgement for the risks. The crisp risk values are shown in Table 8.
For the sake of comparison, Table 8 also shows the traditional risk assessment results.

Occurrence and severity are the two primary characteristics used to assess risks in traditional method. And the final risk values are obtained with 
multiplication of these characteristics. The risk order in traditional risk assessment method is as $\mathrm{R} 1=\mathrm{R} 2=\mathrm{R} 3>$ $\mathrm{R} 6=\mathrm{R} 7>\mathrm{R} 5>\mathrm{R} 4$ whereas in proposed model risk order is follows: $\mathrm{R} 1>\mathrm{R} 5>\mathrm{R} 6>\mathrm{R} 3>\mathrm{R} 4>\mathrm{R} 2>\mathrm{R} 7$.

When these results compared each other, it can be seen that the risks which influenced by more important activities and strategic objectives were evaluated as "more important/risky" with proposed method.

Additionally, there is equality between five risk values among seven figures in traditional method. Proposed model has eliminated this problem and provided convenience to decision makers about prioritizing.

Table 8 . Risk values obtained by the traditional method and proposed method

\begin{tabular}{|c|c|c|c|c|c|c|c|c|}
\hline \multirow{3}{*}{$\begin{array}{l}\frac{n}{\frac{n}{n}} \\
\approx \\
\text { R1 }\end{array}$} & \multicolumn{3}{|c|}{ Traditional Method } & \multicolumn{5}{|c|}{ Modified fuzzy LLSM (+CFCS Defuzzification Method) } \\
\hline & \multirow{2}{*}{\begin{tabular}{|c} 
Severity \\
7
\end{tabular}} & \multirow{2}{*}{$\begin{array}{c}\text { Occurrence } \\
8\end{array}$} & \multirow{2}{*}{$\begin{array}{c}\begin{array}{c}\text { Total Risk } \\
\text { Value }\end{array} \\
56\end{array}$} & \multicolumn{3}{|c|}{ Global Fuzzy Weights } & \multirow{2}{*}{$\begin{array}{c}\begin{array}{c}\text { Crisp } \\
\text { Weights }\end{array} \\
0.1734\end{array}$} & \multirow{2}{*}{$\begin{array}{c}\begin{array}{c}\text { Normalized } \\
\text { Weights }\end{array} \\
15.8210\end{array}$} \\
\hline & & & & $(0.086$ & 0.1734 & $0.293)$ & & \\
\hline $\mathbf{R 2}$ & 8 & 7 & 56 & $(0.073$ & 0.1335 & $0.199)$ & 0.1335 & 12.1805 \\
\hline $\mathbf{R 3}$ & 8 & 7 & 56 & $(0.073$ & 0.1451 & $0.221)$ & 0.1451 & 13.2389 \\
\hline $\mathbf{R 4}$ & 6 & 5 & 30 & $(0.069$ & 0.1455 & $0.239)$ & 0.1455 & 13.2754 \\
\hline $\mathbf{R 5}$ & 8 & 6 & 48 & $(0.091$ & 0.1677 & $0.255)$ & 0.1677 & 15.3009 \\
\hline R6 & 7 & 7 & 49 & $(0.079$ & 0.1982 & $0.254)$ & 0.1982 & 18.0838 \\
\hline $\mathbf{R 7}$ & 7 & 7 & 49 & $(0.072$ & 0.1326 & $0.195)$ & 0.1326 & 12.0984 \\
\hline
\end{tabular}

The above results show that, the proposed methodology offers a more precise risk prioritization in terms of the institutional strategic management approach. Hence, the control activities to be used against the risks would be providing a more accurate and cost-effective planning.

\section{Conclusions}

In this paper we proposed the use of fuzzy logarithmic least squares method (LLSM) in the analytic hierarchy process (AHP), which was modified by Wang et al. ${ }^{54}$, to assess strategic risks in public sector. At a time when risk assessment has an increasing importance for public institutions, this paper provides insight into the various factors related with the problem.

Proposed method tackles the problems about other LLSM approaches' incorrectness in the normalization of local fuzzy weights, infeasibility in deriving the local fuzzy weights of a fuzzy comparison matrix when the lower bound value of a non-normalized fuzzy weight turns out to be greater than its upper bound value, uncertainty of local fuzzy weights for incomplete fuzzy comparison matrices, and unreality of global fuzzy weights. The modified fuzzy LLSM is formulated as a constrained nonlinear optimization model and can directly derive normalized triangular fuzzy weights for both complete and incomplete triangular fuzzy comparison matrices ${ }^{54}$.

The main contribution of this study is to establish a risk assessment model by considering interactions among the strategic objectives, strategic steps (activities) and risks. The examination of the numerical example showed the advantages of the modified fuzzy LLSM in terms of considering interactions among the criteria according to traditional method and its applicability in solving complex multi attribute decision making problems. The other expected improvement is related to the scoring in the risk assessment of decision makers. Opinions of the experts over criteria and alternatives have been evaluated in the construction of the model. Implementation of a fuzzy AHP structure to a real life model is a time consuming process. But the fuzzy AHP model covers and gives the best solution to the vagueness of the pairwise comparison process considerably. The proposed model provides a user friendly implementation of fuzzy AHP for a fuzzy decision support system by using GAMS 
and Microsoft Excel. Using these software applications both in the model construction and data processing phase gives a great flexibility for experts and decision makers. An advantage of the study is to be able to adopt the model for a different fuzzy AHP model in a short time. The proposed methodology also serves as a guideline to the risk analysts. Although fuzzy AHP technique used in the proposed model is computationally intensive, the benefits of risk reduction will outweigh the required cost and time.

In this study, only the interactions among level of criteria were considered and the risk priority was determined on this basis. Future studies may expand the model by analyzing the inter-dependence of criteria and risks.

\section{Acknowledgements}

The authors would like to thank Emre Çalışkan and Emel Kızılkaya for their valuable suggestions and contributions.

\author{
Appendix A. \\ Model (Table 3): \\ sets \\ i $/ 1 * 5 /$ \\ alias (i,j); \\ table $1(\mathrm{i}, \mathrm{j})$ \\ table $m(i, j)$ \\ table $\mathrm{u}(\mathrm{i}, \mathrm{j})$ \\ amac.. $\mathrm{z}=\mathrm{e}=\operatorname{sum}((\mathrm{i}, \mathrm{j}) \$(\operatorname{ord}(\mathrm{j})<>\operatorname{ord}(\mathrm{i})), \operatorname{sqr}(\log (\mathrm{wl}(\mathrm{i}))-$ \\ $\log (w u(j))-\log (1(\mathrm{i}, \mathrm{j})))+\operatorname{sqr}(\log (w m(\mathrm{i}))-\log (w m(j))-$ \\ $\log (\mathrm{m}(\mathrm{i}, \mathrm{j})))+\operatorname{sqr}(\log (w \mathrm{w}(\mathrm{i}))-\log (w \mathrm{l}(\mathrm{j}))-\log (\mathrm{u}(\mathrm{i}, \mathrm{j}))))$; \\ kisit1(i).. $\quad w l(i)+\operatorname{sum}(j \$(\operatorname{ord}(j)<>\operatorname{ord}(i)), w u(j))=g=1$; \\ kisit2(i).. $\quad w(\mathrm{wu}(\mathrm{i})+\operatorname{sum}(\mathrm{j} \$(\operatorname{ord}(\mathrm{j})<>\operatorname{ord}(\mathrm{i})), \mathrm{wl}(\mathrm{j}))=\mathrm{l}=1$; \\ kisit3.. $\quad \operatorname{sum}(i, w m(i))=e=1$; \\ kisit4.. $\quad \operatorname{sum}(i, w l(i)+w u(i))=e=2$; \\ kisit5(i).. $\quad w u(i)=g=w m(i)$; \\ kisit6(i).. $\quad w m(i)=g=w l(i)$; \\ model rabiamodel /all/; \\ solve rabiamodel using nlp minimizing $\mathrm{z}$;
}

\begin{tabular}{|c|c|c|c|}
\hline \multicolumn{4}{|c|}{ Solution (Table 3): } \\
\hline ---- VAR z & $-\mathrm{INI}$ & 3.904 & $+\mathrm{INF}$ \\
\hline ---- VAR wl & & & I \\
\hline LOWER & $\begin{array}{l}\text { LEVEL } \\
0193\end{array}$ & UPPER & MARGINAL \\
\hline $\begin{array}{ll}1 & 1.0000 \mathrm{E}-6 \\
2 & 1.0000 \mathrm{E}-6\end{array}$ & $\begin{array}{l}0.193 \\
0163\end{array}$ & $\begin{array}{l}1.000 \\
1000\end{array}$ & \\
\hline $\begin{array}{l}21.0000 \mathrm{E}-6 \\
31.0000 \mathrm{E}-6\end{array}$ & $\begin{array}{l}0.103 \\
0123\end{array}$ & 1.000 & \\
\hline $\begin{array}{l}1.0000 \mathrm{E}-6 \\
1.0000 \mathrm{E}-6\end{array}$ & 0.125 & 1.000 & \\
\hline $\begin{array}{l}41.0000 \mathrm{E}-6 \\
51.0000 \mathrm{E}-6\end{array}$ & $\begin{array}{l}0.154 \\
0.161\end{array}$ & $\begin{array}{l}1.000 \\
1000\end{array}$ & \\
\hline 5 1.0000E-6 & 0.161 & 1.000 & \\
\hline
\end{tabular}

\begin{tabular}{|c|c|c|c|}
\hline $\begin{array}{l}- \text { VAR wm } \\
\text { LOWER }\end{array}$ & LEVEL & UPPER & MARGINAL \\
\hline $11.0000 \mathrm{E}-6$ & 0.193 & 1.000 & \\
\hline $21.0000 \mathrm{E}-6$ & 0.168 & 1.000 & \\
\hline $31.0000 \mathrm{E}-6$ & 0.197 & 1.000 & \\
\hline $41.0000 \mathrm{E}-6$ & 0.213 & 1.000 & \\
\hline 5 1.0000E-6 & 0.230 & 1.000 & \\
\hline \multicolumn{4}{|l|}{---- VAR wu } \\
\hline LOWER & LEVEL & UPPER & MARGINAL \\
\hline $11.0000 \mathrm{E}-6$ & 0.213 & 1.000 & \\
\hline $21.0000 \mathrm{E}-6$ & 0.186 & 1.000 & \\
\hline $31.0000 \mathrm{E}-6$ & 0.245 & 1.000 & \\
\hline $41.0000 \mathrm{E}-6$ & 0.268 & 1.000 & \\
\hline 5 1.0000E-6 & 0.294 & 1.000 & \\
\hline ---- VAR z & -IN & 3.904 & $+\mathrm{INF}$ \\
\hline
\end{tabular}

\section{References}

1. U.S. Department of Transportation Federal Highway Administration, Guide to risk assessment and allocation for highway construction management, (2006).

2. United Kingdom Her Majesty's Treasury, The Orange Book, Management of Risks - Principles and Concepts, (2004).

3. S. Bonvicini, P. Leonelli, and G. Spadoni., Risk analysis of hazardous materials transportation: evaluating uncertainty by means of fuzzy logic, in Journal of Hazardous Materials, 62 (1998) 59-74.

4. H. Frantzich, Risk analysis and fire safety engineering, in Fire Safety Journal, 31 (1998) 313-329.

5. W.L. McGill, B.M. Ayyub and M. Kaminskiy, Risk analysis for critical asset protection, in Risk Analysis, 27(5) (2007) 1265-1281.

6. Z.Y. Han and W.G. Weng, An integrated quantitative risk analysis method for natural gas pipeline network, in Journal of Loss Prevention in the Process Industries, 23 (2010) 428-436.

7. A.J. Bailer, R.B. Noble and M.W. Wheeler, Model Uncertainty and risk estimation for experimental studies of quantal responses, in Risk Analysis: An International Journal, 25(2) (2005) 291-299.

8. D.L. Kelly and C.L. Smith, Bayesian inference in probabilistic risk assessment-The current state of the art, in Reliability Engineering \& System Safety, 94(2) (2009) 628-643.

9. D.E. Nordgard and K. Sand, Application of Bayesian networks for risk analysis of MV air insulated switch operation, in Reliability Engineering \& System Safety, 95(12) (2010) 1358-1366.

10. I.U. Sikder, M. Sanchita and K. Tarun, Knowledge-based risk assessment under uncertainty for species invasion,in Risk Analysis: An International Journal, 26(1) (2006) 239252

11. K. Pan, D. Marhavilas and E. Koulouriotis, A riskestimation methodological framework using quantitative assessment techniques and real accidents' data: 
Application in an aluminum extrusion industry, in Journal of Loss Prevention in the Process Industries, 21 (2008) 596-603.

12. Y.-M. Wang, J. Liu, T.M.S. Elhag, An integrated AHPDEA methodology for bridge risk assessment, in Computers \& Industrial Engineering, 54(3) (2008) 513525.

13. R. Schulz, S. Stehle, D. Elsaesser, S. Matezki, A. Müller, M. Neumann, R. Ohliger, J. Wogram and K. Zenker, Geodata-based probabilistic risk assessment and management of pesticides in germany: a conceptual framework, in Integrated Environmental Assessment \& Management, 5(1) (2009) 69-79.

14. T. Aven and B. Heide, Reliability and validity of risk analysis, in Reliability Engineering \& System Safety 94(11) (2009) 1862-1868.

15. A. Srivastava and J.R. Gupta, New methodologies for security risk assessment of oil and gas industry, in Process Safety\&Environmental Protection: Transactions of the Institution of Chemical Engineers, 88(6) (2010) 407-412.

16. R. Dash, Risk Assessment Techniques for Software Development, in European Journal of Scientific Research, 42(4) (2010) 615-622.

17. S. Syachrani, H.S. Jeong, V. Rai, M. Jin, M.J. Chae and T. Iseley, A risk management approach to safety assessment of trenchless technologies for culvert rehabilitation, in Tunnelling and Underground Space Technology, 25(6) (2010) 681-688.

18. S.M. Mousavi, R. Tavakkoli, A. Azaron, S.M.H. Mojtahedi and H. Hashemi, Risk assessment for highway projects using jackknife technique, in Expert Systems with Applications, 38 (2011) 5514-5524.

19. S.M. Chen, Fuzzy group decision making for evaluating the rate of aggregative risk in software development, in Fuzzy Sets and Systems, 118 (2001) 75-88.

20. N.R. Sankar and B.S. Prabhu, Modified approach for prioritization of failures in a system failure mode and effects analysis, in International Journal of Quality \& Reliability Management, 18(3) (2001) 324-335.

21. A. Pillay and J. Wang, Modified FMEA using approximate reasoning, in Reliability Engineering and System Safety, 79(1) (2003) 69-85.

22. H.N. Cho, H.H. Choi and Y.B. Kim, A risk assessment methodology for incorporating uncertainties using fuzzy concepts, in Reliability Engineering \& System Safety, 78(2) (2002) 173-183.

23. Y. Endo and K. Horiuchi, Risk analysis of fuzzy control systems with $(\mathrm{n}+1)$-inputs and 1-output FLC, in Fuzzy Sets and Systems, 147(3) (2004) 341-361.

24. Y. Sun, R. Huang, D. Chen and H. Li, Fuzzy set-based risk evaluation model for real estate projects, in Tsinghua Science And Technology, 13(1) (2008) 158-164.

25. C. Kahraman and İ. Kaya, Fuzzy Process Accuracy Index to Evaluate Risk Assessment of Drought Effects in Turkey, in Human and Ecological Risk Assessment, 15 (2009) 789-810.
26. A. Pinto, I. Nunes and R. Ribeiro, Occupational risk assessment in construction industry - overview and reflection, in Safety Science, 49 (2011) 616-624.

27. S.J. Chen and S.M. Chen, Fuzzy risk analysis based on similarity measures of generalized fuzzy numbers, in IEEE Transactions on Fuzzy Systems, 11(1) (2003) 45-46.

28. J.H. Chen and S.M. Chen, A new method for ranking generalized fuzzy numbers for handling fuzzy risk analysis problems, in Proc. $9^{\text {th }}$ Conference on Information Sciences, (Kaohsiung, Taiwan, Republic of China, 2006) pp. 1196-1199.

29. S.J. Chen and S.M. Chen, Fuzzy risk analysis based on the ranking of generalized trapezoidal fuzzy numbers, in Applied Intelligence, 26(1) (2007) 1-11.

30. K.J. Schmucker, Fuzzy sets, natural language computations, and risk analysis (MD: Computer Science Press, 1984).

31. T.C. Tang and L.C. Chi, Predicting multilateral trade credit risks: Comparisons of logic and fuzzy logic models using ROC curve analysis, in Expert Systems with Applications, 28(3) (2005) 547-556.

32. S.M. Chen, New methods for subjective mental workload assessment and fuzzy risk analysis, in Cybernetics and Systems, 27(5) (1996) 449-472.

33. H.S. Lee, An optimal aggregation method for fuzzy opinions of group decision, in Proc. of the 1999 IEEE Int. Conf. on Systems, Man and Cybernetics, Vol.3 (1999) pp. 314-319.

34. S.M. Chen and S.J. Chen, Fuzzy risk analysis based on measures of similarity between interval-valued fuzzy numbers, in Computers \& Mathematics with Applications, 55(8) (2008) 1670-1685.

35. S.M. Chen and S.J. Chen, Fuzzy risk analysis based on similarity measures between interval-valued fuzzy numbers and interval-valued fuzzy number arithmetic operators, in Expert Systems with Applications, 36(3-2) (2009a) 6309-6317.

36. S.M. Chen and S.J. Chen, Fuzzy risk analysis based on ranking generalized fuzzy numbers with different heights and different spreads, in Expert Systems with Applications, 36(3-2) (2009b) 6833-6842.

37. S.H. Wei and S.M. Chen, A new similarity measure between generalized fuzzy numbers, in Proc. 3rd Int. Conf. on Soft Computing and Intelligent Systems and 7th Int. Symp. on Advanced Intelligence Systems, (Tokyo, Japan, 2006), pp. 315-320.

38. S.H. Wei and S.M. Chen, A new approach for fuzzy risk analysis based on similarity measures of generalized fuzzy numbers, in Expert Systems with Applications, 36(1) (2009) 589-598.

39. Z. Xu, S. Shang, W. Qian and W. Shu, A method for fuzzy risk analysis based on the new similarity of trapezoidal fuzzy numbers, in Expert Systems with Applications, 37(3) (2010) 1920-1927.

40. S.R. Hejazi, A. Doostparast and S.M. Hosseini, An improved fuzzy risk analysis based on a new similarity 
measures of generalized fuzzy numbers, in Expert Systems with Applications, 38(8) (2011) 9179-9185.

41. B. Gaudenzi and A. Borghesi, Managing risks in the supply chain using the AHP method, in International Journal of Logistics Management, 17(1) (2006) 114-136.

42. T. Zayed, M. Amer and J. Pan, Assessing risk and uncertainty inherent in Chinese highway projects using AHP, in International Journal of Project Management, 26(4) (2008) 408-419.

43. M. Dağdeviren, Decision making in equipment selection: an integrated approach with AHP and PROMETHEE, in Journal of Intelligent Manufacturing, 19(4) (2008)397406.

44. A. Ouédraogo, A. Groso and T. Meyer, Risk analysis in research environment - Part II: Weighting lab criticity index using the analytic hierarchy process, in Safety Science, 49(6) (2011) 785-793.

45. M. An, Y. Chen, C.J. Baker, A fuzzy reasoning and fuzzyanalytical hierarchy process based approach to the process of railway risk information: A railway risk management system, in Information Sciences, 181(18) (2011) 39463966.

46. X. Wang, H.K. Chan, R.W.Y. Yee, I. Diaz-Rainey, A twostage fuzzy-AHP model for risk assessment of implementing green initiatives in the fashion supply chain, in International Journal of Production Economics, 135(2) (2012) 595-606.

47. K.F.R. Liu and J.H. Lai, Decision support for environmental impact assessment: A hybrid approach using fuzzy logic and fuzzy analytic network process, in Expert Systems with Applications 36 (2009) 5119-5136.

48. H.H. Chen, A.H.I. Lee and H. Kang, A model for strategic selection of feeder management systems: A case study, in Electrical Power and Energy Systems, 32 (2010) 421-427.

49. D. Xia and B. Chen, A comprehensive decision-making model for risk management of supply chain, in Expert Systems with Applications, 38 (2011) 4957-4966.

50. Y.M. Wang and T.M.S. Elhag, Fuzzy TOPSIS method based on alpha level sets with an application to bridge risk assessment, in Expert Systems With Applications, 31(2) (2006a) 309-319.

51. K. Zhang, C. Kluck and G. Achari, A comparative approach for ranking contaminated sites based on the risk assessment paradigm using fuzzy PROMETHEE, in Environmental Management, 44(5) (2009) 952-967.

52. M. Dağdeviren, İ. Yüksel and M. Kurt, A fuzzy analytic network process (ANP) model to identify faulty behavior risk (FBR) in 'work system'”, in Safety Science, 46 (2007) 771-783.

53. Y.M. Wang and T.M.S. Elhag, "On the normalization of internal and fuzzy weights", in Fuzzy Sets and Systems, 157 (2006 b) 2456-2471.

54. Y.M. Wang, T.M.S. Elhag and Z. Hua, A modified fuzzy logarithmic least squares method for fuzzy analytic hierarchy process, in Fuzzy Sets and Systems, 157 (2006c) 3055-3071.
55. T.L. Saaty, The analytic Hierarchy Process, (New York: McGraw Hill, 1980).

56. C.E. Bozdag, C. Kahraman and D. Ruan, Fuzzy group decision making for selection among computer integrated manufacturing systems, in Computers in Industry, 51 (2003) 13-29.

57. C. Kahraman, U. Cebeci and Z. Ulukan, Multi-criteria supplier selection using fuzzy AHP, in Logistic Information Management, 16-6 (2003) 382-394.

58. C. Kahraman, T. Ertay and G. Büyüközkan, A fuzzy optimization model for QFD planning process using analytic network approach, in European Journal of Operational Research, 171 (2006) 390-411.

59. E. Tolga, M.L. Demircan and C. Kahraman, Operating system selection using fuzzy replacement analysis and analytic hierarchy process, in International Journal of Production Economics, 97 (2005) 89-117.

60. P.J.M. Van Laarhoven and W. Pedrycz, A fuzzy extension of Saaty's priority theory, in Fuzzy Sets and Systems, 11 (1983) 229-241.

61. J.J. Buckley, Fuzzy hierarchical analysis", Fuzzy Sets and Systems 17 (1985) 233-247.

62. C.G.E. Boender, J.G. De Graan and F.A. Lootsma, Multicriteria decision analysis with fuzzy pairwise comparisons, in Fuzzy Sets and Systems 29 (1989) 133-143.

63. M. Kwiesielewicz, The logarithmic least squares and the generalized pseudoinverse in estimating ratios, in European Journal of Operational Research, 93 (1996) 611-619.

64. M. Kwiesielewicz, A note on the fuzzy extension of Saaty's priority theory, in Fuzzy Sets and Systems, 95 (1998) 161-172.

65. R. $\mathrm{Xu}$ and $\mathrm{X}$. Zhai, Fuzzy logarithmic least squares ranking method in analytic hierarchy process, in Fuzzy Sets and Systems, 77 (1996) 175-190.

66. R. Xu, Fuzzy least-squares priority method in the analytic hierarchy process, in Fuzzy Sets and Systems, 112 (2000) 359-404.

67. D.Y. Chang, Applications of the extent analysis method on fuzzy AHP, in European Journal of Operational Research, 95 (1996) 649-655.

68. K.J. Zhu, Y. Jing and D.Y. Chang, A discussion on extent analysis method and application of fuzzy AHP, in European Journal of Operational Research, 116 (1999) 450-456.

69. L.C. Leung and D. Cao, On consistency and ranking of alternatives in fuzzy AHP, in European Journal of Operational Research, 124 (2000) 102-113.

70. J.J. Buckley, T. Feuring and Y. Hayashi, Fuzzy hierarchical analysis revisited, in European Journal of Operational Research, 129 (2001) 48-64.

71. R. Csutora and J.J. Buckley, J.J., Fuzzy hierarchical analysis: the Lamda-Max method, in Fuzzy Sets and Systems, 120 (2001) 181-195.

72. L. Mikhailov, Deriving priorities from fuzzy pairwise comparison judgments, in Fuzzy Sets and Systems, 134 (2003) 365-385. 
73. Y.M. Wang, Y. Luo and Z. Hua, On the extent analysis method for fuzzy AHP and its applications, in European Journal of Operational Research, 186(2) (2008) 735-747.

74. A. Jiménez, S. Ríos-Insua and A. Mateos, A decision support system for multiattribute utility evaluation based on imprecise assignments, in Decision Support Systems, 36 (2003) 65-79.

75. H.J. Zimmermann, Fuzzy Set Theory and Its Applications, 2nd edn. (Kluwer-Nijhoff, Boston, 1991).
76. M. Dağdeviren and İ. Yüksel, A fuzzy analytic network process (ANP) model for measurement of the sectoral competititon level (SCL), in Expert Systems with Applications, 37 (2010) 1005-1014.

77. S. Opricovic and G.H. Tzeng, Defuzzification within a multicriteria decision model, in International Journal of Uncertainty, Fuzziness and Knowledge-Based Systems, 11(5) (2003) 635-652.

78. H. Lin, An application of fuzzy AHP for evaluating course website quality, in Computers and Education, 54(4) (2010) 877-888. 